\title{
Evaluation of Angiotensin I Converting Enzyme Inhibitory Activity by an FIA Combined with Biosensors
}

\author{
Kanthi J. M. Abesundara, Motonobu Higuchi, Toshiro Matsui, and Kiyoshi Matsumoto ${ }^{\dagger}$ \\ Laboratory of Food Analysis, Division of Food Biotechnology, Department of Bioscience and Biotechnology, \\ Faculty of Agriculture, Graduate School of Kyushu University, Hakozaki, Higashi, Fukuoka 812-8581, Japan
}

(Received November 19, 2001; Accepted January 23, 2002)

\begin{abstract}
Angiotensin I converting enzyme (ACE) plays an important role in the regulation of blood pressure. Therefore, inactivation or inhibition of ACE is quite effective in lowering blood pressure or preventing the pathogenesis of hypertension. ${ }^{1}$ The ACE inhibitors such as captopril and enalapril have made it possible to treat hypertention effectively, for they act as the antihypertensive drugs. In the field of food chemistry, much attention is devoted to discover food materials with antihypertensive efficacy from natural resources. Accordingly, determination of ACE inhibitory activity is important in ACE inhibitor screening. Several methods for the measurement of ACE inhibitory activity have been developed, including colorimetric $^{2}$ and HPLC, ${ }^{3}$ with that of Cushman and Cheung ${ }^{4}$ being most commonly utilized. But this method requires many steps, including extraction of products and evaporation. Here we describe a method for the assay of ACE inhibitory activity using a flow injection analytical system combined with immobilized enzymes by quantifying the amount of hippuric acid liberated from hippuryl-hystidyl-leucine (HHL) by the action of ACE. The high sensitivity of enzymes coupled with the electrochemical signal transducer should ideally result in an enzyme electrode capable of measuring the concentration of the substrate in a medium containing a diverse mixture of other compounds.
\end{abstract}

\section{Experimental}

\section{Reagents}

Aminoacylase (EC 3.5.1.14, from pig kidney, $3500 \mathrm{U} \mathrm{mg}^{-1}$ ) was purchased from Wako Chemicals (Osaka, Japan). D-Amino acid oxidase (D-AOD, EC 1.4.3.3, from hog kidney, $15 \mathrm{U} \mathrm{mg}^{-1}$ ) were from Boehringer Mannheim $\mathrm{GmbH}$. Glutaraldehyde $(25 \%$ w/w) and D-alanine were from Nacalai Tesque (Kyoto, Japan). Aminopropyl controlled-pore glass (APCPG, 80 - 120 mesh) and angiotensin I converting enzyme (ACE, EC 3.4.15.1, from rabbit lung, $4 \mathrm{U} \mathrm{mg}^{-1}$ ) were from Sigma (St. Louis, MO). Hippuric acid and HHL were obtained from Katayama Chemicals (Osaka, Japan) and Peptide Institute, Inc. (Osaka), respectively. Poly sodium 4-styrene sulfonate and poly L-lysine bromate were obtained from Aldrich (Milwaukee, WI). All other chemicals were of analytical reagent grade and were used as received.

\section{Procedure}

Enzyme reactors were prepared as reported previously ${ }^{5}$ and were blocked with L-alanine. The reaction scheme, that we used to quantify hippuric acid is shown in Fig. 1. The carrier solution (50 mM phosphate buffer) containing the substrate of D-AOD (0.4 mM D-alanine) was pumped through the system; thus, hydrogen peroxide was constantly produced in the D-AOD reactor, giving a high blank base line, and it was monitored amperometrically on the platinum electrode. The concentration of hippuric acid was determined in an indirect way, by monitoring the decrease of the hydrogen peroxide production by benzoate which acts as an inhibitor on D-AOD, resulting a negative peak from the base line. ${ }^{6}$ Benzoate was produced from hippuric acid by the action of the aminoacylase reactor. To increase the production of benzoate and thus get significant amperometric responses, the reaction time between aminoacylase and hippuric acid was extended using a stopped flow analytical technique that was described in our previous paper. $^{7}$

\section{Flow system}

The amperometric measurements were carried out using a stopped flow injection system with an electrochemical flowthrough cell. The cell was equipped with a reference electrode $(\mathrm{Ag} / \mathrm{AgCl})$, a working electrode $(\mathrm{Pt})$ and a counter electrode (stainless-steel). The carrier solution was pumped through the system by an HPLC pump through an air dumper at a flow rate of $1 \mathrm{ml} \mathrm{min}{ }^{-1}$. The main flow line was divided into two lines by a six way-switching valve. The six way-switching valve was
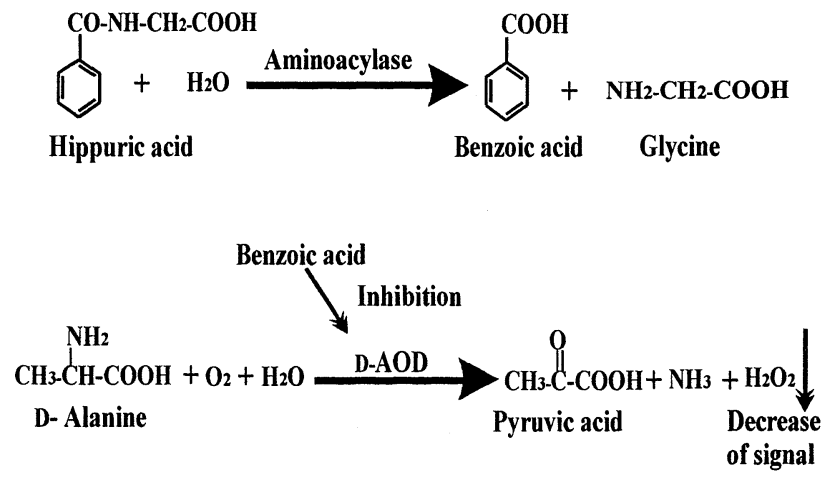
Fig. 1 Reaction scheme of the hippuric acid quantification system.

$\doteqdot$ To whom correspondence should be addressed. 
Table 1 The $\mathrm{IC}_{50}$ values of some ACE inhibitors measured by the FIA method and by the spectrophotometric method

\begin{tabular}{lccc}
\hline \multirow{2}{*}{ Inhibitor } & \multicolumn{3}{c}{$\mathrm{IC}_{50}(\mu \mathrm{M}) \pm \mathrm{SD}$} \\
\cline { 2 - 4 } & FIA & Spectrophotometry & Other \\
\hline Captopril & $0.039 \pm 0.0089$ & $0.044 \pm 0.0127$ & $0.04^{\mathrm{a}}$ \\
Val-Tyr & $18.4 \pm 0.67$ & $17.2 \pm 0.58$ & $22^{\mathrm{b}}$ \\
Gly-Tyr & $256 \pm 28.3$ & $268 \pm 9.5$ & $259^{\mathrm{c}}$ \\
Leu-Tyr & $76 \pm 14.8$ & $81 \pm 9.8$ & $79^{\mathrm{d}}$ \\
\hline
\end{tabular}

a. Ref. 12. b. Ref. 13. c. Ref. 14. d. Ref. 15.

switched to the aminoacylase reactor for hippurate intake or to a blank column for by-pass flow. The blank column was the same size as the enzyme reactor and contained only L-alanine blocked APCPG as a support. The potential of $+0.65 \mathrm{~V}$ was applied on Pt electrode vs. $\mathrm{Ag} / \mathrm{AgCl}$ by a potentiostat. The surface of the Pt electrode was covered with a poly ion complex membrane made of poly L-lysine hydrobromide and poly sodium 4-styrenesulfonate. ${ }^{8}$ The flow system was operated at room temperature.

Standard assay method of ACE activity and preparation of samples for FIA

The standard batch assay was performed according to the methods reported by Lieberman ${ }^{9}$ and Yamamoto et al. ${ }^{10}$ with some modifications. Preparation of samples for FIA was similar to the spectrophotometric method up to the incubation. In the FIA method, after incubation, reactions were terminated by immersing the test tubes in a boiling water bath. Then, samples were appropriately diluted with carrier buffer and injected. The response of hippurate was monitored amperometrically.

\section{Results and Discussion}

As described in our previous paper, ${ }^{7}$ this method has been applied to the determination of ACE activity and compared to the spectrophotometric method. A linear relation was obtained between negative peak current and logarithms of hippuric acid concentration in the range of 15 to $1000 \mu \mathrm{M}$. The method showed good agreement with the conventional Lieberman's modified method, giving a correlation coefficient of 0.97. In the present study, $\mathrm{IC}_{50}$ values of some ACE inhibitors were measured by the new method and were compared to the spectrophotometric method. The results are summarized in Table 1. The concentration of ACE inhibitor required to inhibit $50 \%$ of the ACE activity was defined as $\mathrm{IC}_{50}$. In the spectrophotometric method, the inhibitory ratio (\%) is estimated as follows:

Inhibitory ratio $=\left(A_{\mathrm{C}}-A_{\mathrm{S}}\right) /\left(A_{\mathrm{C}}-A_{\mathrm{B}}\right) \times 100$.

Here, $A_{\mathrm{C}}, A_{\mathrm{S}}$ and $A_{\mathrm{B}}$ represent the absorbance of control, sample and blank, respectively. In the FIA system, converting the peak height to enzymatic activity $\left(\mathrm{mU} \mathrm{ml}^{-1}\right)$ can be accomplished through the transformation of the concentration of the hippuric acid to $\mathrm{mU} \mathrm{ml}^{-1}$ directly. Therefore, peak height was used instead of absorbance:

$$
\text { Inhibitory ratio }=\left(\mathrm{PH}_{\mathrm{C}}-\mathrm{PH}_{\mathrm{S}}\right) /\left(\mathrm{PH}_{\mathrm{C}}-\mathrm{PH}_{\mathrm{B}}\right) \times 100 \text {. }
$$

Here, $\mathrm{PH}_{\mathrm{C}}, \mathrm{PH}_{\mathrm{S}}$ and $\mathrm{PH}_{\mathrm{B}}$ represent the peak height of control, sample and blank, respectively. Each datum of the inhibitory ratio to calculate $\mathrm{IC}_{50}$ value was the mean of triplicates. According to Table $1, \mathrm{IC}_{50}$ value of captopril was found to be nearly $0.04 \mu \mathrm{M}$ by both method. This was similar to the value that was reported by Ondetti. This method was also applied to measure the $\mathrm{IC}_{50}$ value of some peptides, including Val-Tyr, ${ }^{11,13}$ Gly-Tyr ${ }^{14}$ and Leu-Tyr. ${ }^{15}$ The results are in good agreement with the results obtained from the spectrophotometric method and from the other methods that were previously reported which are cited in the Refs. $12-15$. In addition, the performance of the proposed method was judged by calculating the Students's tand F-tests for each inhibitor. At the 95\% confidence level, the calculated t- and F-values do not exceed the theoretical values, indicating that there is no significant difference between the values of each inhibitor that were obtained from the FIA and from the spectrophotometric method. Moreover, the result of the paired t-test was $t=0.3693$, and no significant difference between two methods under $p<0.05$ was found.

On consideration of interference, many food components did not interfere with the system. The remains can be prevented by polyion complex on Pt electrode, except for high concentrations of ascorbic acid and ethanol as discussed in our previous papers. ${ }^{6,7}$ In addition, small amounts of interference substances can be neglected as the original samples are diluted more than 40-fold before injection. However, ascorbic acid and polyphenol compounds ${ }^{16}$ have to be removed before measurement. In conclusion, FIA system also can be used for determination of ACE inhibitory activity.

\section{References}

1. M. Nicholls, A. Richards, and M. Agarwal, J. Human Hypertension, 1998, 12, 295.

2. T. Matsui, H. Matsufuji, and Y. Osajima, Biosci. Biotech. Biochem., 1992, 56, 517.

3. M. Horiuchi, K. Fujima, T. Terashima, and T. Iso, J. Chromatogr., 1982, 233, 123.

4. D. W. Cushman and H.-S. Cheung, Biochem. Pharmacol., 1971, 20, 1637.

5. K. Matsumoto and K. Waki, Anal. Chim. Acta, 1999, 380, 110.

6. M. Higuchi, K. J. M. Abesundara, and K. Matsumoto, J. Flow Injection Anal., 2000, 17, 194.

7. K. J. M. Abesundara, M. Higuchi, and K. Matsumoto, Anal. Sci., 2001, 17(suppl.), i1411.

8. F. Mizutani, S. Yabuki, and Y. Hirata, Denki Kagaku, 1995, 63, 1100.

9. J. Lieberman, Am. J. Med., 1975, 59, 365.

10. S. Yamamoto, I. Toida, and K. Iwai, Nihon Kyoushitsu Kaishi, 1980, 18, 297.

11. H. Matsufuji, T. Matsui, S. Ohshige, T. Kawasaki, K. Osajima, and Y. Osajima, Biosci. Biotech. Biochem., 1995, 59, 1398.

12. M. A. Ondetti, B. Rubin, and D. W. Cushman, Science, 1977, 196, 441.

13. H. S. Cheung, F. L. Wang, M. A. Ondetti, E. F. Sabo, and D. W. Cushman, J. Biol. Chem, 1980, 255, 401.

14. Y. Saito, K. Wanesaki, A. Kawato, and S. Imayasu, Biosci. Biotech. Biochem., 1994, 58, 1767.

15. E. Seki, K. Osajima, H. Matsufuji, T. Matsui, and Y. Osajima, Nippon Nogeikagaku Kaishi, 1996, 70, 21.

16. K. Matsumoto, H. Matsubara, H. Ukeda, and Y. Osajima, Agric. Biol. Chem., 1989, 53, 2347. 